\title{
Homocysteine-induced oxidative stress through TLR4/NF-кB/DNMT1-mediated LOX-1 DNA methylation in endothelial cells
}

\author{
SHENG-CHAO MA ${ }^{1 *}$, YIN-JU HAO ${ }^{1 *}$, YUN JIAO ${ }^{2}$, YAN-HUA WANG $^{1}$, LING-BO XU $^{1}$, \\ CAI-YAN MAO ${ }^{1}$, XIAO-LING YANG ${ }^{1}$, AN-NING YANG $^{1}$, JUE TIAN $^{1}$, MING-HAO ZHANG $^{1}$, \\ SHAO-JU JIN ${ }^{1}$, HUA XU ${ }^{1}$, YI-DENG JIANG ${ }^{1}$ and HUI-PING ZHANG ${ }^{3}$ \\ ${ }^{1}$ School of Basic Medical Sciences, Ningxia Medical University; Departments of ${ }^{2}$ Infectious Diseases and \\ ${ }^{3}$ Prenatal Diagnosis Center, General Hospital of Ningxia Medical University, Yinchuan, Ningxia 750004, P.R. China
}

Received January 29, 2017; Accepted August 22, 2017

DOI: $10.3892 / \mathrm{mmr} .2017 .7753$

\begin{abstract}
Atherosclerosis (AS) is a progressive disease of multifactorial origin, which occurs in response to endothelial injury. Increased homocysteine (Hcy) is considered a major cause of endothelial dysfunction, oxidative stress and DNA methylation; however, the mechanisms remain to be fully elucidated. The aim of the present study was to investigate whether Hcy causes injury to endothelial cells (ECs) by the effect of lectin-like oxidized-low density lipoprotein receptor-1 (LOX-1) DNA methylation through toll-like receptor 4(TLR4)/nuclear factor (NF) $-\kappa B / D N A$ methyltransferase (DNMT)1. The ECs were treated with different concentrations of Hcy, and it was found that Hcy promoted the expression of TLR4, leading to EC injury. The effect of oxidative stress was analyzed by measuring superoxide dismutase, malondialdehyde and hydrogen peroxide in the ECs. In addition, the association between NF- $\kappa \mathrm{B}$ and DNMT1 was examined by treatment of the ECs with pyrrolidine dithiocarbamate (PDTC). The results suggested that Hcy induced LOX-1 DNA hypomethyaltion to promote the expression levels of LOX-1. Taken together, Hcy injured the ECs through the effect of methylation and trans-sulfuration metabo-

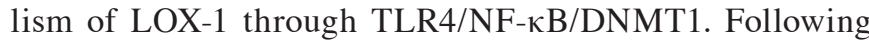

Correspondence to: Professor Yi-Deng Jiang, School of Basic Medical Sciences, Ningxia Medical University, 1160 Shengli Street, Yinchuan, Ningxia 750004, P.R. China

E-mail: jydcan@126.com

Professor Hui-Ping Zhang, Department of Prenatal Diagnosis Center, General Hospital of Ningxia Medical University, 804 Shengli Street, Yinchuan, Ningxia 750004, P.R. China

E-mail: zhp19760820@163.com

*Contributed equally

Key words: homocysteine, oxidative stress, toll-like receptor/nuclear factor- $\kappa \mathrm{B} / \mathrm{DNA}$ methyltransferase 1, DNA methylation, endothelial cells injury to the ECs, lipids, particularly ox-LDL, accumulated in the sub-endothelial layer to promote the formation of AS.

\section{Introduction}

Atherosclerosis (AS), the underlying cause of cardiovascular disease, is characterized by multiple key events, including endothelial cell (EC) injury, conversion of lesion-resident macrophages into foam cells, and smooth muscle cell proliferation (1). EC injury is the key initiating step in the formation of AS (2), which is induced by multiple mechanisms, including oxidative stress, endoplasmic reticulum stress, and insulin resistance. Oxidative stress has increasingly been investigated to explain EC injury (3). Homocysteine (Hcy) is an independent risk factor for AS and is involved as an early atherosclerotic promoter, which enhances EC injury (4). However, the potential causative role of Hcy in EC injury by oxidative stress remains to be fully elucidated.

EC injury can be triggered by oxidized low-density lipoprotein (ox-LDL) in AS, and associated investigations have indicated that ox-LDL and its receptor, lectin-like ox-LDL receptor-1 (LOX-1), are important in the development of EC injury (5). LOX-1 is a scavenger receptor, which allows the uptake of ox-LDL into ECs, and the expression of this receptor is involved in the formation of atherosclerotic vascular lesions; LOX-1 involved at various steps in the pathogenesis of AS and expressed at high levels in atherosclerotic lesions $(6,7)$. Simultaneously, it has been suggested that anti-LOX-1 antibody significantly suppresses EC injury in the absence of hypertension (8). Based on genetic and functional investigations, LOX-1 may be a novel biomarker and target in EC injury of AS. One of main mechanisms involved in AS induced by Hcy involves DNA methylation (9), and our previous study suggested that Hcy induced the hypomethylation of genes associated with AS, including platelet-derived growth factor (10). Therefore, it was hypothesized that Hcy injures ECs through mediating LOX-1 DNA methylation, however, the mechanism remains to be elucidated.

DNA methylation is an epigenetic change, which arises from the addition of a methyl group at the carbon-5 position 
of cytosine residues, this process is mediated by DNA methyltransferases (DNMTs), a family of enzymes, including DNMT1, DNMT3a and DNMT3b (11). DNMT1, the principal DNMT in mammalian cells, is a large dynamic enzyme with multiple regulatory features, which can control DNA methylation in cells (12). A number of studies have reported that DNMT1 is an alternative mechanism of DNA methylation, and nuclear factor $-\kappa \mathrm{B}(\mathrm{NF}-\kappa \mathrm{B})$ is one of the transcriptional factors regulating the transcription of several genes involved in numerous critical pathways $(13,14)$, this transcriptional factor is potentially targeted at various levels. An associated study has suggested that bortezomib results in the downregulation of DNMT1 via the specificity protein-1 (SP1)/NF- $\mathrm{B}$ pathway and induces genomic DNA hypomethylation in leukemia cells (15). NF- $\kappa \mathrm{B}$ is a key transcription factor pathway in several key biological processes, including inflammation, apoptosis and immune responses, which is a key in the toll-like receptor 4 (TLR4) signaling pathway (16). TLR4 is a pattern-recognizing receptor, forming the first line of defense. A previous study suggested that the lipopolysaccharide (LPS) -induced inflammatory response may be mediated through the reduced expression of TLR4 to suppress the activation of NF- $\kappa$ B $(17,18)$. Simultaneously, TLR4/NF- $\kappa$ B is important in monocyte-endothelium adhesion, at least in part.

The aim of the present study was to investigate whether elevated Hcy levels are associated with EC injury and to examine whether Hcy-induced oxidative stress occurs through TLR4/NF- $\mathrm{B} / \mathrm{DNMT1-mediated} \mathrm{LOX-1} \mathrm{DNA} \mathrm{methylation} \mathrm{in}$ ECs.

\section{Materials and methods}

EC culture. The CRL-1730 EC line was purchased from American type culture collection (Manassas, VA, USA). The cells were treated with different concentrations $(0,50,100,200$ and $500 \mu \mathrm{mol} / \mathrm{l}$ ) of Hcy (Sigma; Merck Millipore, Darmstadt, Germany) or $100 \mu \mathrm{mol} / 1$ Hcy with $30 \mu \mathrm{mol} / 1$ vitamin $\mathrm{B}_{12}$ and $30 \mu \mathrm{mol} / 1$ folic acid at $37^{\circ} \mathrm{C}$ in an incubator with $5 \% \mathrm{CO}_{2}$ for $72 \mathrm{~h}$. The ECs were divided into a further three groups: untreated cells, endothelial cells treated with Hcy $(100 \mu \mathrm{mol} / \mathrm{l})$, endothelial cells treated with Hcy $(100 \mu \mathrm{mol} / \mathrm{l})$ and $10 \mu \mathrm{mol} / \mathrm{l}$ pyrrolidine dithiocarbamate (PDTC; Sigma-Aldrich; Merck KGaA, Darmstadt, Germany).

Cell viability assessment. Methylthiazoletetrazolium (MTT) (Sigma-Aldrich; Merck KGaA) was used for the evaluation of cell viability. The cells were grown in 96-well microtiter plates at a density of $1 \times 10^{4}$ cells in $200 \mu \mathrm{l}$ per well. When cells grew to $80 \%$ confluence, $20 \mu \mathrm{l}$ MTT $(5 \mathrm{mg} / \mathrm{ml})$ was added to each well and incubated at $37^{\circ} \mathrm{C}$ for $4 \mathrm{~h}$. The supernatant was discarded and $150 \mu \mathrm{l}$ dimethylsulfoxide was added to each well. Following incubation for $10 \mathrm{~min}$, the plates were read on a microplate reader (Bio-Rad Laboratories, Inc., Hercules, CA, USA) at $490 \mathrm{~nm}$.

Measurement of NF- $\kappa B, D N M T 1$ and ox-LDL concentrations using ELISA. The cells were collected and samples were determined using the following ELISA kits, NF- $\kappa \mathrm{B}$ (cat. no. DY1795) and ox-LDL (cat. no. DYC4299) obtained from R\&D Systems, Inc. (Minneapolis, MN, USA), and the
DNMT1 ELISA kit (cat. no. ab113469; Abcam, Cambridge, UK) according to the manufacturers' protocols.

Measurement of superoxide dismutase (SOD), malondialdehyde (MDA) and hydrogen peroxide $\left(\mathrm{H}_{2} \mathrm{O}_{2}\right)$ concentrations via colorimetry. The levels of SOD (Nanjing Jiancheng Bioengineering Institute, Nanjing, China), MDA (Nanjing Jiancheng Bioengineering Institute) and $\mathrm{H}_{2} \mathrm{O}_{2}$ (Nanjing Jiancheng Bioengineering Institute) were determined using colorimetry according to the manufacturer's protocol. The absorbance was read on a microplate reader at $550 \mathrm{~nm}$.

Reverse transcription-quantitative polymerase chain reaction (RT-qPCR) analysis. Total RNA was isolated from the cultured cells using a Tri-Reagent kit (Invitrogen; Thermo Fisher Scientific, Inc.). The SYBR Green kit (Fermentas; Thermo Fisher Scientific, Inc.) was then used for RT-qPCR analysis. Glyceraldehyde-3-phosphate dehydrogenase (GAPDH) was applied as an internal control for TLR-4, LOX-1 and DNMT1 in the ECs. The primers are listed in Table I and the reaction system was: $2 \mathrm{X}$ SYBR mixture $25 \mu \mathrm{l}$, Forward primer $1 \mu \mathrm{l}$, Reverse primer $1 \mu \mathrm{l}$, cDNA $2 \mu \mathrm{l}$ and Rnase-free water up to $50 \mu \mathrm{l}$. The thermal cycler (Funglyn Biotech, Inc., Toronto, ON, Canada) conditions comprised an initial activation step at $95^{\circ} \mathrm{C}$ for $5 \mathrm{~min}$, followed by a 2 -step PCR program of $95^{\circ} \mathrm{C}$ for $15 \mathrm{sec}$, annealing temperatures for $15 \mathrm{sec}$ and at $72^{\circ} \mathrm{C}$ for $30 \mathrm{sec}$ for 30 cycles. Subsequently, the relative changes in the mRNA expression levels of TLR-4, LOX-1 and DNMT1 were determined by fold-change analysis, in which the degree of change was calculated as $2^{-\Delta \Delta \mathrm{Cq}}$, where $\mathrm{Cq}=\left(\mathrm{Cq}_{\text {gene }}-\mathrm{Cq}_{\mathrm{GAPDH}}\right)$ treatment - $\left(\mathrm{Cq}_{\text {gene }}-\mathrm{Cq}_{\mathrm{GAPDH}}\right)$ control (19).

Western blot analysis. Total proteins were isolated from the cells using cell lysis buffer (Keygen Biotech Co., Ltd., Nanjing, China). Equal amounts of protein $(\sim 80 \mu \mathrm{g})$ and known molecular weight marker were loaded onto $12 \%$ sodium dodecyl sulfate-polyacrylamide gels (SDS-PAGE) and were transferred to PVDF membrane by electrophoresis at $300 \mathrm{~mA}$ for $50 \mathrm{~min}$ at $4^{\circ} \mathrm{C}$, the membrane was then blocked in $10 \mathrm{ml} \mathrm{5 \%} \mathrm{skimmed} \mathrm{milk} \mathrm{for} 2 \mathrm{~h}$ at room temperature with gentle agitation on a platform shaker. The LOX-1 and TLR-4 proteins were detected using LOX-1 (cat. no. sc-66155) and TLR-4 (cat. no. sc-13593) antibodies were obtained from Santa Cruz Biotechnology, Inc., (Dallas, TX, US) diluted 1:500, and $\beta$-actin protein was detected using a rabbit anti-human $\beta$-actin antibody (cat. no. sc-70319, Santa Cruz Biotechnology, Inc.) diluted 1:2,000; all primary antibodies were incubated at $4^{\circ} \mathrm{C}$. The secondary antibody (goat anti-mouse IgG-HRP, cat. no. sc-2031, 1:2,000; Santa Cruz Biotechnology, Inc.) was added for $2 \mathrm{~h}$ at room temperature. The protein bands were visualized and analyzed by the Gel Documentation and Analysis System ChemiDoc XRS system with Image Lab software, version 4.1 (Bio-Rad Laboratories, Inc.) and calculated by the gray value of the bands.

Nested touchdown methylation-specific PCR (ntMSP) analysis. Total genomic DNA was extracted from the cultured cells using a DNA isolation kit (Sigma-Aldrich; Merck Millipore) according to the manufacturer's protocol, and genomic DNA $(1 \mu \mathrm{g})$ was bisulfite modified (Sigma-Aldrich; 
Table I. Primer sequences of TLR-4, LOX-1, DNMT1 and GAPDH for reverse transcription-quantitative polymerase chain reaction analysis.

\begin{tabular}{|c|c|c|c|c|}
\hline Gene & Primer & Sequence $\left(5^{\prime}-3^{\prime}\right)$ & Temperature $\left({ }^{\circ} \mathrm{C}\right)$ & Length (bp) \\
\hline \multirow[t]{2}{*}{ TLR4 } & Forward & ATAAGTGTCGAACTCCCTC & 51 & 138 \\
\hline & Reverse & GCTCATTCCTTACCCAGT & & \\
\hline \multirow[t]{2}{*}{ LOX-1 } & Forward & AATGATAGAAACCCTTGC & 46 & 132 \\
\hline & Reverse & TTCCCAGTTAAATGAGCC & & \\
\hline \multirow[t]{2}{*}{ DNMT1 } & Forward & GGAGCCCAGCAAGAGTA & 51 & 141 \\
\hline & Reverse & GGGAGACACCAGCCAAAT & & \\
\hline \multirow[t]{2}{*}{ GAPDH } & Forward & AGAAGGCTGGGGCTCATTT & 51 & 146 \\
\hline & Reverse & AGGGGCCACAGTCTTCG & & \\
\hline
\end{tabular}

TLR4, toll-like receptor 4; LOX-1, lectin-like oxidized-low density lipoprotein receptor-1; DNMT1, DNA methyltransferase 1; GAPDH, glyceraldehyde-3-phosphate dehydrogenase.

Table II. Primer sequences of lectin-like oxidized-low density lipoprotein receptor-1 for nested touchdown methylation-specific polymerase chain reaction analysis.

\begin{tabular}{llc}
\hline Primer & \multicolumn{1}{c}{ Sequence (5'-3') } & Length (bp) \\
\hline Left outer & TTAGTATTGTGGG & 251 \\
& AGGTTGAGGTAG & \\
Right outer & TAAAATTTCACCC & \\
& TTATTACCCAAA & 137 \\
Left M & TTGAAAATATAAA & \\
& ATAATTAGTCGG & \\
Right M & TAAATTACAATAA & \\
& CATAATCTCG & \\
Left $\mathrm{U}$ & TTGAAAATATAAA & \\
& ATAATTAGTTGG & \\
Right $\mathrm{U}$ & AATAAATTACAATA & \\
& ACATAATCTCAAC & \\
\hline
\end{tabular}

M, methylated; U, unmethylated.

Merck Millipore). The detection of methylation levels was conducted as previously described (20). The reaction conditions of PCR were as follows: $94^{\circ} \mathrm{C}$ for $45 \mathrm{sec}, 68.3^{\circ} \mathrm{C}$ for $45 \mathrm{sec}$, and $72^{\circ} \mathrm{C}$ for $45 \mathrm{sec}$ for 20 cycles, followed by a $0.5^{\circ} \mathrm{C}$ decrease of $53.3^{\circ} \mathrm{C}$ every cycle for 20 cycles. The second step of PCR was performed with conventional PCR primers under the following reaction conditions: $94^{\circ} \mathrm{C}$ for $45 \mathrm{sec}, 67^{\circ} \mathrm{C}$ for $45 \mathrm{sec}$, and $72^{\circ} \mathrm{C}$ for $45 \mathrm{sec}$ for 20 cycles, followed by a $0.5^{\circ} \mathrm{C}$ decrease of $52^{\circ} \mathrm{C}$ every cycle for 20 cycles, and ending with extension at $72^{\circ} \mathrm{C}$ for $5 \mathrm{~min}$. Primer sequences are listed in Table II.

Statistical analysis. Prism 5.0 (GraphPad Software, Inc., La Jolla, CA, USA) was used for data processing. Experiments were performed at least in triplicate. Results were expressed as mean \pm standard error of the mean $(\bar{x} \pm S)$. Two-way analysis of variance was used for comparisons between

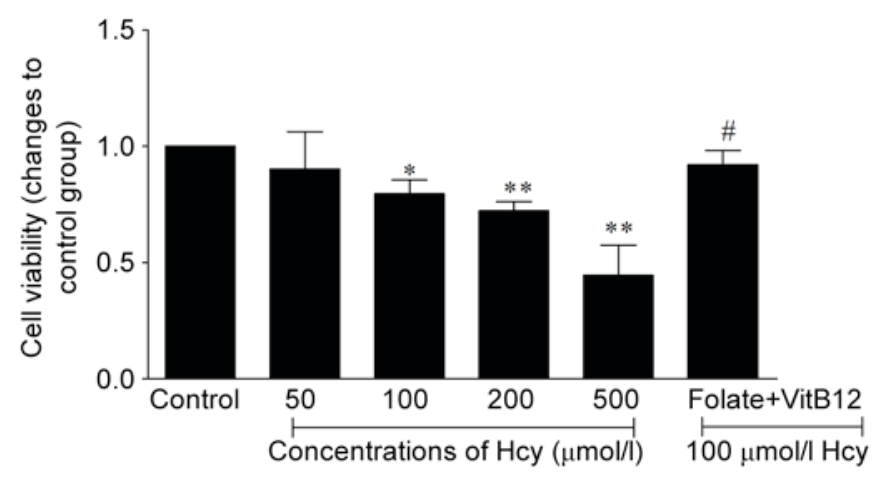

Figure 1. Effects of Hcy on EC viability analyzed using methylthiazoletetrazolium. ECs were cultured in medium containing Hcy $(0,50,100,200$ and $500 \mu \mathrm{mol} / 1)$ or $100 \mu \mathrm{mol} / 1 \mathrm{Hcy}$ with $30 \mu \mathrm{mol} \mathrm{VitB12}$ and $30 \mu \mathrm{mol}$ folate for $72 \mathrm{~h}$. The control group contained untreated cells. ${ }^{*} \mathrm{P}<0.05$ and ${ }^{* *} \mathrm{P}<0.01$, compared with the control group; ${ }^{\#} \mathrm{P}<0.05$, compared with the $100 \mu \mathrm{mol} / 1$ Hcy group. EC, endothelial cell; Hcy, homocysteine; VitB12, vitamin $\mathrm{B}_{12}$.

groups and additional analysis was performed using Student-Newman-Keuls test for multiple comparisons within treatment groups. $\mathrm{P}<0.05$ was considered to indicate a statistically significant difference.

\section{Results}

Hcy impairs EC viability. Following incubation of the ECs with Hcy for $72 \mathrm{~h}$, the viability of ECs was determined using an MTT assay. As shown in Fig. 1, Hcy affected EC viability in a dose-dependent manner, and found that cell activities were decreased by 21,28 , and $56 \%$ in the 100,200 , and $500 \mu \mathrm{mol} / 1$ Hcy group, respectively $(\mathrm{P}<0.05$ or $\mathrm{P}<0.01)$. When treated with folic acid and vitamin $\mathrm{B}_{12}$, the viability of the ECs was increased by 1.15 -fold, compared with that in the $100 \mu \mathrm{mol} / 1$ Hcy group. Taken together, these results suggested that Hcy induced EC injury.

Hcy decreases the activity of SOD and increases levels of MDA, $\mathrm{H}_{2} \mathrm{O}_{2}$ and $\mathrm{ox}-\mathrm{LDL}$ in ECs. Hcy is an independent risk factor for several major pathologies in cardiovascular disease, and elevated Hcy is important in various pathologies by increasing 
Table III. Levels of SOD, MDA, $\mathrm{H}_{2} \mathrm{O}_{2}$ and ox-LDL in endothelial cells.

\begin{tabular}{lcccc}
\hline Group & SOD $(\mathrm{U} / \mathrm{mg}$ prot $)$ & MDA $(\mathrm{nmol} / \mathrm{mg}$ prot $)$ & $\mathrm{H}_{2} \mathrm{O}_{2}(\mathrm{mmol} / \mathrm{l})$ & ox-LDL $(\mathrm{mg} / \mathrm{l})$ \\
\hline $0 \mu \mathrm{mol} / 1$ & $156.28 \pm 10.35$ & $24.52 \pm 2.29$ & $11.63 \pm 1.67$ & $0.72 \pm 0.06$ \\
$50 \mu \mathrm{mol} / 1$ & $148.23 \pm 7.40$ & $27.90 \pm 2.00$ & $16.49 \pm 1.58$ & $0.87 \pm 0.09$ \\
$100 \mu \mathrm{mol} / 1$ & $135.96 \pm 6.25^{\mathrm{a}}$ & $30.71 \pm 1.58^{\mathrm{a}}$ & $21.44 \pm 2.61^{\mathrm{b}}$ & $1.04 \pm 0.12^{\mathrm{b}}$ \\
$200 \mu \mathrm{mol} / 1$ & $111.89 \pm 6.18^{\mathrm{a}}$ & $37.49 \pm 5.09^{\mathrm{a}}$ & $36.81 \pm 3.42^{\mathrm{a}}$ & $1.11 \pm 0.18^{\mathrm{a}}$ \\
$500 \mu \mathrm{mol} / 1$ & $103.40 \pm 4.89^{\mathrm{a}}$ & $39.23 \pm 3.81^{\mathrm{a}}$ & $46.03 \pm 4.15^{\mathrm{a}}$ & $1.50 \pm 0.20^{\mathrm{a}}$ \\
$100 \mu \mathrm{mol} / 1+\mathrm{V}+\mathrm{F}$ & $146.06 \pm 3.60$ & $28.66 \pm 2.62$ & $15.01 \pm 2.23$ & $0.83 \pm 0.06$ \\
\hline
\end{tabular}

$100 \mu \mathrm{mol} / \mathrm{l}+\mathrm{V}+\mathrm{F}$ group, co-incubation with $100 \mu \mathrm{mol} / 1 \mathrm{Hcy}, 30 \mu \mathrm{mol} / 1$ folate and $30 \mu \mathrm{mol} / 1$ vitamin $\mathrm{B}_{12}$ for $72 \mathrm{~h}$. Data expressed as the mean \pm standard deviation. ${ }^{\mathrm{a}} \mathrm{P}<0.01$ and ${ }^{\mathrm{b}} \mathrm{P}<0.05$, compared with the $0 \mu \mathrm{mol} / 1$ Hcy group. Hcy, homocysteine; SOD, superoxide dismutase; MDA, malondialdehyde; $\mathrm{H}_{2} \mathrm{O}_{2}$, hydrogen peroxide; ox-LDL, oxidized low density lipoprotein.

the production of $\mathrm{H}_{2} \mathrm{O}_{2}$, which affects the antioxidant defense systems (21). In the present study, $\mathrm{H}_{2} \mathrm{O}_{2}$ concentrations were increased in the 100, 200 and $500 \mu \mathrm{mol} / 1 \mathrm{Hcy}$ groups $(\mathrm{P}<0.05$ and $\mathrm{P}<0.01)$. The results also demonstrated that the activity of the antioxidant enzyme SOD was markedly decreased in parallel with the levels of MDA in the Hcy-treated cells. Taken together, these results suggested that Hcy injures ECs by oxidative stress. Ox-LDL is considered to be a biomarker of in vivo oxidative stress in AS, and elevated oxidative stress and superoxide anion formation in vascular cells can promote the conversion of LDL to ox-LDL, contributing to endothelial dysfunction and AS. In the present study, the change in the levels of ox-LDL was consistent with the trend observed for the oxidative stress indicators, increasing by 1.44-, 1.54- and 2.1-fold in the 100, 200 and $500 \mu \mathrm{mol} / 1 \mathrm{Hcy}$ groups, respectively $(\mathrm{P}<0.01$; Table III). The levels decreased by $20.2 \%$ in the folate and vitamin $B_{12}$-treated cells.

Hcy promotes expression levels of TLR4 and LOX-1 in ECs. TLR4 is a central mediator of the innate immune response, which is important in the defense mechanism against microorganisms (22). In the present study, the mRNA levels if TLR4 were upregulated by 16.6-, 18.7- and 30.3-fold in the 100, 200 and $500 \mu \mathrm{mol} / 1 \mathrm{Hcy}$ groups, compared with that in the untreated group, respectively. In addition, the protein expression of TLR4 was increased by 1.8-, 1.9- and 2.0-fold in the 100 and 200 and $500 \mu \mathrm{mol} / 1 \mathrm{Hcy}$ groups, respectively $(\mathrm{P}<0.01$; Fig. 2A and B). The expression of TLR4 was decreased when the cells were treated with folic acid and vitamin $B_{12}$. As the level of TLR4 increased with the increase in Hcy, TLR4 may be important in EC injury induced by Hcy.

LOX-1 is a type II membrane glycoprotein in ECs, which has been implicated in atherosclerotic plaque formation, progression and destabilization (23). When the cells were treated with different concentrations of Hcy for $72 \mathrm{~h}$, the mRNA expression of LOX-1 was promoted in the Hcy groups $(\mathrm{P}<0.05$ and $\mathrm{P}<0.01$; Fig. $2 \mathrm{C})$, and decreased when the cells were treated with folic acid and vitamin $\mathrm{B}_{12}$. The protein levels of LOX-1 were increased by 1.7 -fold in the $100 \mu \mathrm{mol} / 1$ Hcy group (Fig. 2A and C) and when the cells were treated with folic acid and vitamin $\mathrm{B}_{12}$, the expression levels of LOX-1 decreased by $26 \%$. These findings suggested that Hcy promoted the expression of LOX-1, leading to EC injury.
Hcy induces LOX-1 DNA hypomethylation in ECs. In the present study, Hcy suppressed the levels of LOX-1 DNA methylation by in the 100, 200 and $500 \mu \mathrm{mol} / 1$ Hcy groups (Fig. 3A and $\mathrm{B} ; \mathrm{P}<0.01$ ) while, when treated with folate and vitamin $\mathrm{B}_{12}$, LOX-1 DNA methylation levels were increased, compared with $100 \mu \mathrm{mol} / \mathrm{l}$ Hcy treated cells. These data also suggested that the mRNA levels of DNMT1 were decreased in the Hcy-treated cells (Fig. 3C), and the protein expression of DNMT1 was suppressed in cells treated with increasing concentrations of Hcy (Fig. 3D). Taken together, Hcy appeared to decrease the levels of LOX-1 DNA methylation by reducing the levels of DNMT1. Combined with the results obtained on the expression levels of LOX-1, these results suggested that Hcy may induce LOX-1 DNA hypomethylation to promote the expression levels of LOX-1.

$N F-\kappa B$ decreases the levels of DNMT1 in ECs. Hcy can promote the secretion of NF- $\mathrm{kB}$, and the present study found that Hcy induced the levels of NF- $\mathrm{KB}$ in ECs by 1.6-, 1.9- and 2.3 -fold in the 100, 200 and $500 \mu \mathrm{mol} / 1 \mathrm{Hcy}$ groups, respectively (Fig. 4A; $\mathrm{P}<0.05$ and $\mathrm{P}<0.01$ ), whereas the level was decreased by $28.8 \%$ following treatment of the cells with folate and vitamin $\mathrm{B}_{12}(\mathrm{P}<0.05)$. Previous studies have suggested that the NF- $\mathrm{KB}$ signaling pathway is potentially targeted at various levels, including nuclear translocation, DNA binding and via methyl transferases. The present study hypothesized that NF- $\kappa B$ may be associated with DNMT1. Therefore, the cells were treated with pyrrolidine dithiocarbamate (PDTC), which suppresses the activity of $\mathrm{NF}-\kappa \mathrm{B}$, to confirm the association between NF- $\mathrm{KB}$ and DNMT1. The results suggested that, the PDTC-induced suppression of the activity of NF- $\mathrm{kB}$ led to increased levels of DNMT1 (Fig. 4B and C). Taken together, these findings suggested that Hcy may result in DNA hypomethylation by inducing the activation of NF- $\mathrm{KB}$ and further decreasing the expression of DNMT1.

\section{Discussion}

Studies have confirmed that elevated levels of Hcy are a cause of EC injury and can promote the formation of AS $(24,25)$. In the present study, it was demonstrated that Hcy induced EC injury, which was the main mechanism in the development of AS induced by Hcy. 
A
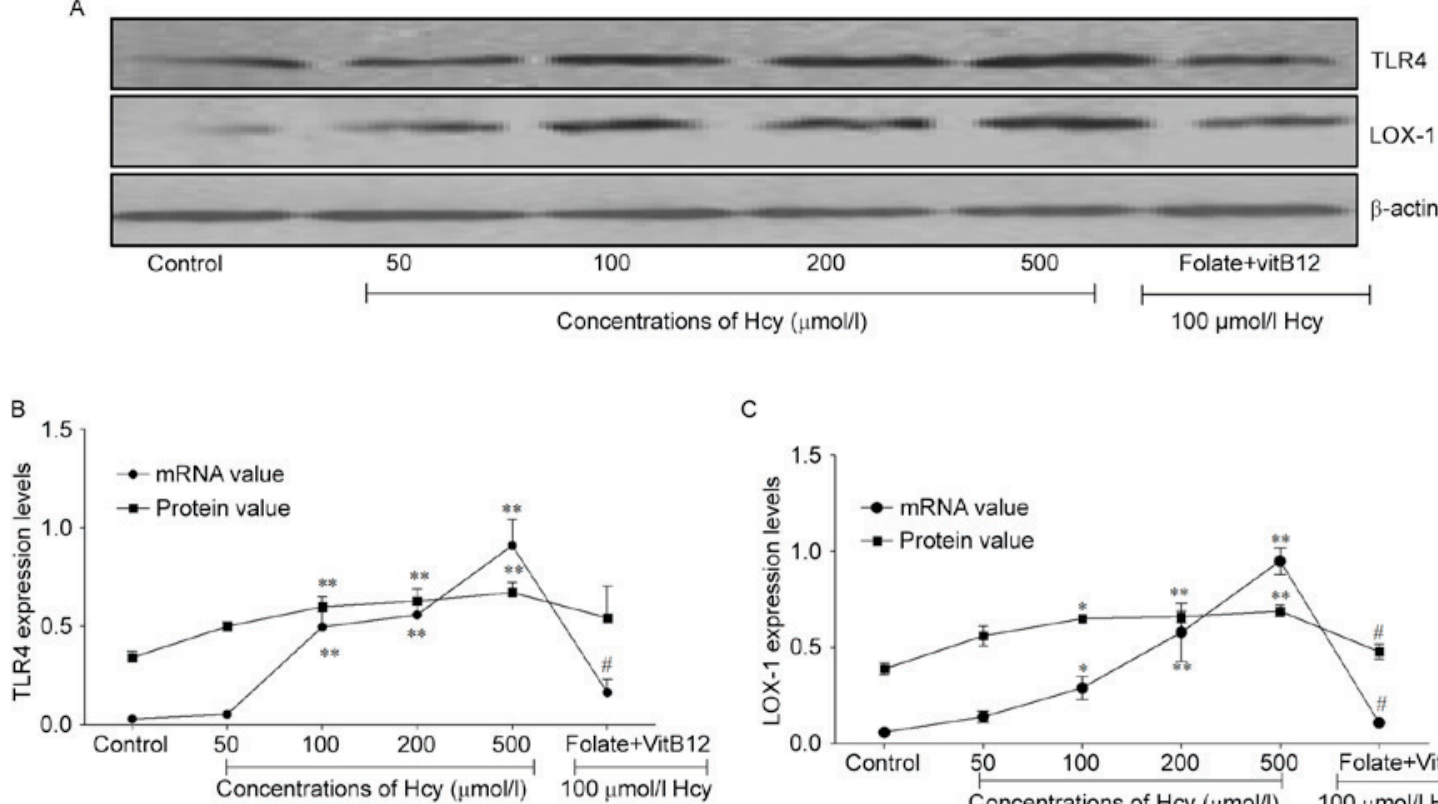

Figure 2. Hcy promotes the expression of TLR4 and LOX-1 in ECs. (A) Protein expression of LOX-1 and TLR4, detected using western blot analysis in ECs treated with different concentrations of Hcy for 72 h. (B) Statistical analysis of expression levels of TLR4, detected using reverse transcription-quantitative polymerase chain reaction (RT-qPCR) and western blot analyses in ECs treated with different concentrations of Hcy for 72 h. (C) Statistical analysis of expression levels of LOX-1 detected using RT-qPCR and western blot analysis in ECs treated with different concentrations of Hcy for 72 h. The control group contained untreated cells; the folate+VitB12 group contained ECs treated with $30 \mu \mathrm{mol} / 1$ folate, $30 \mu \mathrm{mol} / 1 \mathrm{VitB} 12$ and $100 \mu \mathrm{mol} / 1 \mathrm{Hcy}$ for $72 \mathrm{~h}$. *P<0.05 and ${ }^{* *} \mathrm{P}<0.01$, compared with the control group; ${ }^{*} \mathrm{P}<0.05$, compared with the $100 \mu \mathrm{mol} / 1$ Hcy group. EC, endothelial cell; Hcy, homocysteine; VitB12, vitamin $\mathrm{B}_{12}$; TLR4, toll-like receptor 4; LOX-1, lectin-like oxidized-low density lipoprotein receptor-1; RT-qPCR, reverse transcription-quantitative polymerase chain reaction.

Oxidative stress is a condition in which the balance between the production of reactive oxygen species (ROS) and level of antioxidants is significantly disturbed and results in damage to cells by excessive ROS production. $\mathrm{O}_{2} \bullet-, \mathrm{H}_{2} \mathrm{O}_{2}$ and $\mathrm{OH} \bullet$, as the ROS produced, are sensitively controlled by several antioxidant enzymes, including SOD and MDA (26). Accumulating evidence suggests that elevated plasma Hcy affects the oxidant-antioxidant balance in the body following endothelial injury (27). In the present study, $\mathrm{H}_{2} \mathrm{O}_{2}$ concentrations were higher in the Hcy groups and the activity of antioxidant enzyme SOD was decreased, whereas the levels of MDA were increased in the cells under hyperhomocysteinemia. Taken together, these results suggested that oxidative stress induced the imbalance of redox reactions and that Hcy may injure ECs, which produce high levels of ROS through oxidative stress imbalance. This evidence provides scope for subsequent investigations.

LOX-1 was originally identified as the major receptor for ox-LDL in ECs. A feedback exists involving ox-LDL and LOX-1, in which ox-LDL can induce the secretion of LOX-1, then more ox-LDL can be uptaken by LOX-1 in early phase of AS (28). The present study suggested that Hcy promoted ox-LDL and LOX-1 expressions in ECs. Hcy is a sulfur amino acid that can induce oxidative stress by trans-sulfuration and increasing evidence suggests that oxidative stress occurs in response to EC injury, which can oxidize LDL to produce ox-LDL. LOX-1 is one of the scavenger receptors and Hcy has been shown to upregulate scavenger receptors, as reported for the expression of $\mathrm{CD} 36$ at atherogenic lesion sites in apoE $\mathrm{E}^{-1}$ female mice (29). However, the regulation of gene expression is affected by various factors under elevated Hcy, including DNA methylation, which is a focus with AS.
DNA methylation serves as an important mechanism which controls gene expression in AS (30). As shown in the present study, the levels of LOX-1 DNA methylation were significantly decreased in the Hcy groups. Hcy is involved in a one-carbon transfer reaction, which is also important for DNA methylation. In Hcy metabolism, S-adenosylmethionine (SAM) is a metabolic intermediate, which is synthesized from methionine catalyzed by methionine adenosyltransferase, providing methyl group moieties in several transmethylation reactions (31). SAM is converted into $\mathrm{S}$-adenosylhomocysteine (SAH), which is the sole metabolic precursor of Hcy in a reversible reaction catalyzed by SAH hydrolase and can inhibit DNMT1. It has been confirmed that DNA methylation patterns depend on DNMT1, and the results of the present study found that Hcy decreased the levels of DNMT1.

$\mathrm{NF}-\mathrm{\kappa B}$ is a key transcription factor which is responsible for several biological processes, and it has been identified as a member of the structurally-related eukaryotic transcription factor family and regulates inducible gene expression (32). In the present study, data showed that Hcy increased the levels of NF- $\mathrm{kB}$, whereas DNMT1 was suppressed in the Hcy groups. In order to further examine the association between NF- $\mathrm{kB}$ and DNMT1, PDTC, an antioxidant suppressing the activity of $\mathrm{NF}-\mathrm{\kappa B}$, was used, and it was found that NF- $\mathrm{KB}$ downregulated DNMT1. A possible mechanism for this involves the translocation of NF- $\mathrm{KB}$ to the nucleus, binding to specific DNA sequences and promoting the transcription of target genes. DNMT1 has been shown to interact with the transcription factors $\mathrm{Sp} 1, \mathrm{Sp} 3$ and signal transducer and activator of transcription (STAT) 3, with an STAT3-DNMT1-HDAC1 complex binding to the promoter of phosphatase-1 (33), and Sp1/NF- $\mathrm{kB}$ DNA-binding 


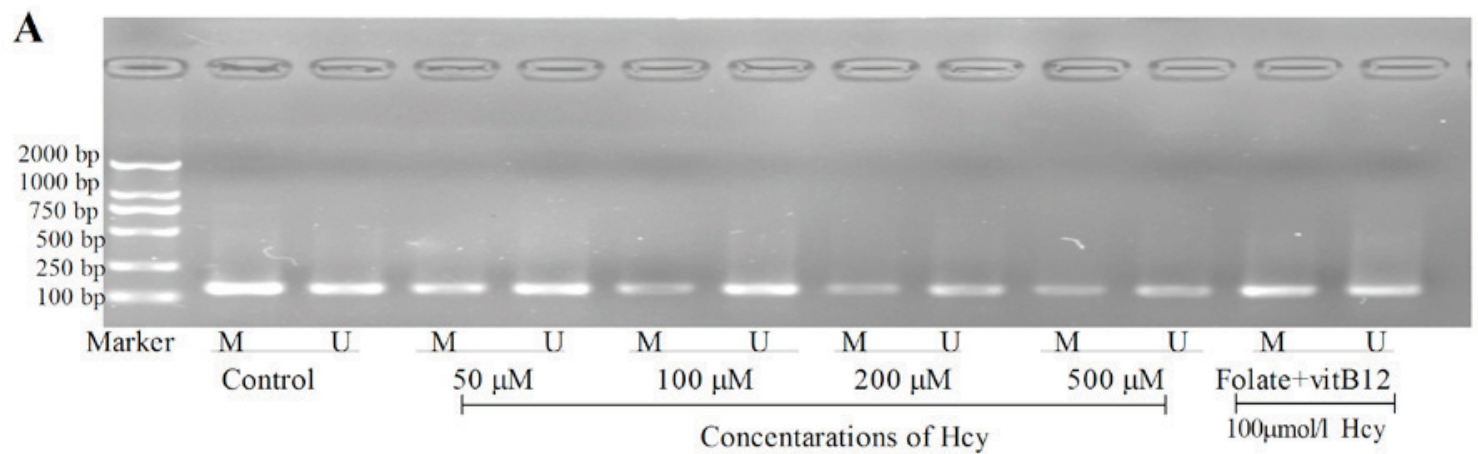

B

C
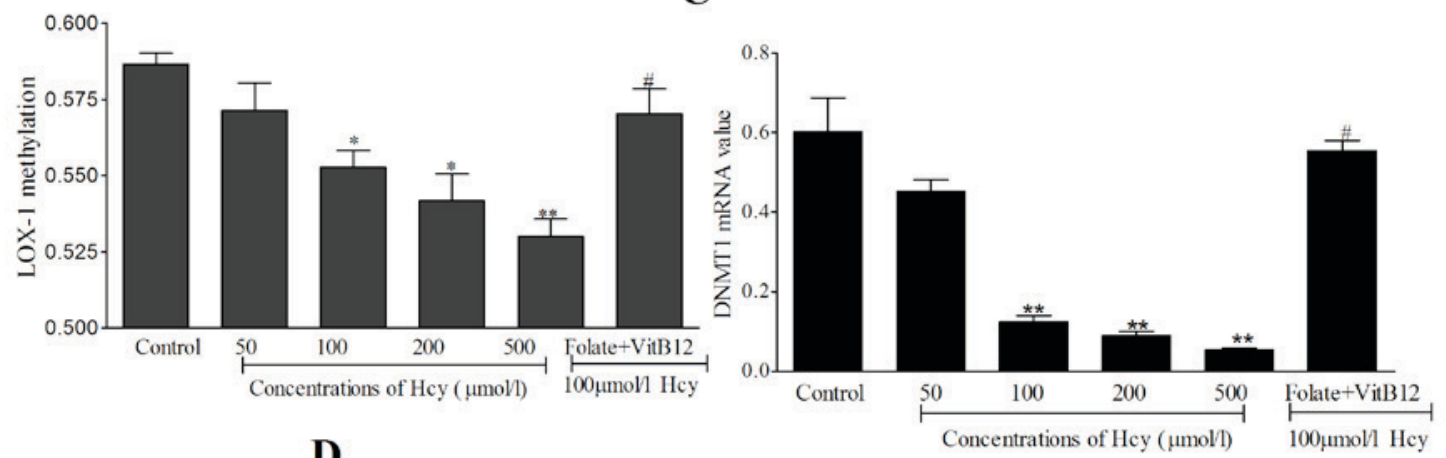

D

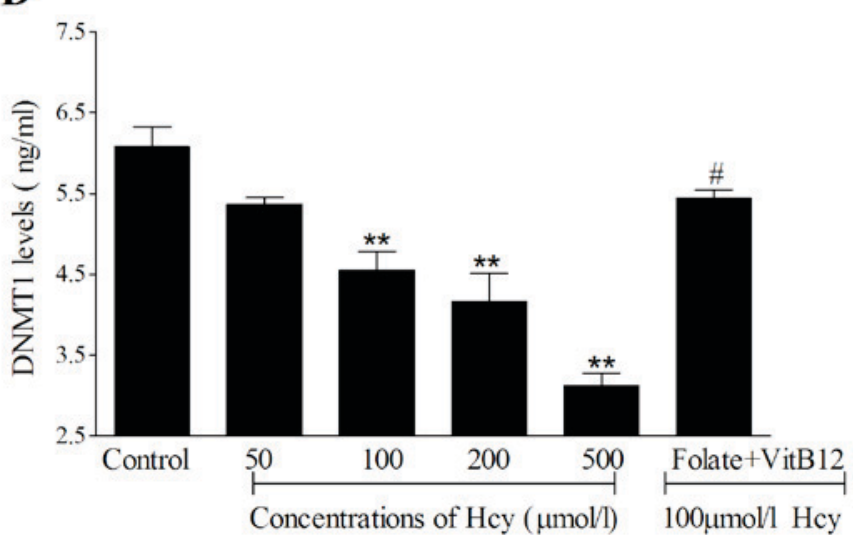

Figure 3. Methylation of LOX-1 and expression of DNMT1. (A) PCR product of LOX-1 DNA methylation. (B) Statistical analysis of the levels of LOX-1 DNA methylation. (C) mRNA levels of DNMT1 were detected using reverse transcription-quantitative PCR in ECs following treatment with Hcy. (D) Protein expression levels of DNMT1 were measured using ELISA following treatment of the ECs with Hcy for $72 \mathrm{~h}$. The control group contained untreated cells. In the folate $+V_{i t B}$ group, ECs were treated with $30 \mu \mathrm{mol} / 1$ folate, $30 \mu \mathrm{mol} / 1$ BitB12 and $100 \mu \mathrm{mol} / 1 \mathrm{Hcy}$ for $72 \mathrm{~h}$. The product length of methylation-specific primer was $137 \mathrm{bp}$; the product length of unmethylation-specific primer was $139 \mathrm{bp} .{ }^{*} \mathrm{P}<0.05$ and ${ }^{* *} \mathrm{P}<0.01$, compared with the control group; ${ }^{*} \mathrm{P}<0.05$, compared with the $100 \mu \mathrm{mol} / 1$ Hcy group. Marker, DNA marker (top to bottom, 2,000, 1,000, 750, 500, 250 and $100 \mathrm{bp}$ ); EC, endothelial cell; Hcy, homocysteine; VitB12, vitamin $\mathrm{B}_{12}$; DNMT1, DNA methyltransferase 1; M, amplified band by methylation-specific primer; U, amplified band by unmethylation-specific primer; PCR, polymerase chain reaction.
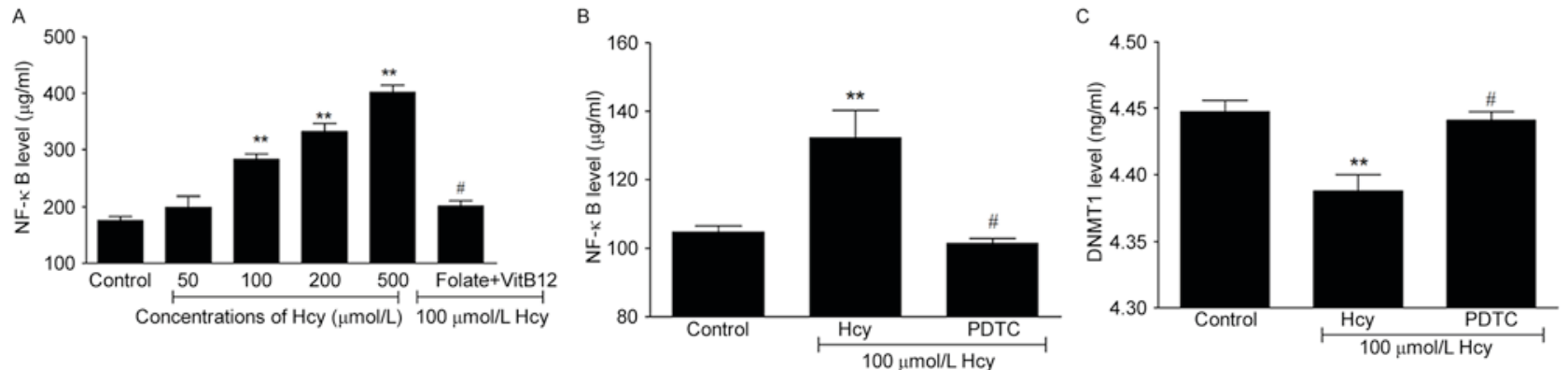

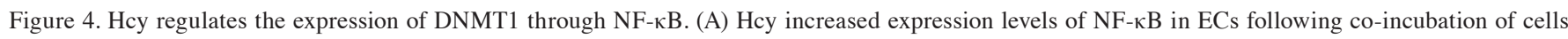
with Hcy. (B) Levels of NF-кB were analyzed in ECs following co-incubation with PDTC. (C) Following co-incubation of ECs with PDTC, levels of DNMT1 were analyzed. Control group, untreated cells; Hcy group, ECs co-incubated with $100 \mu$ mol/l Hcy for 72 h; PDTC group, ECs treated with $100 \mu$ mol/l Hcy and $10 \mu \mathrm{mol} / 1$ PDTC for $72 \mathrm{~h} .{ }^{* *} \mathrm{P}<0.01$, compared with the control group; ${ }^{*} \mathrm{P}<0.05$, compared with the $100 \mu \mathrm{mol} / 1$ Hcy group. EC, endothelial cell; Hcy,

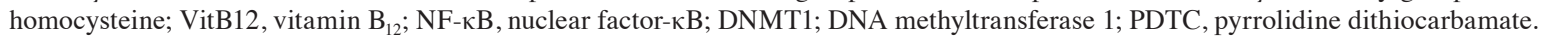


decreasing the expression of DNMT1. Investigations of DNA hypomethylation have suggested that Hcy induces oxidative stress to activate $\mathrm{NF}-\kappa \mathrm{B}$, possibly by generating ROS (34). Taken together, NF- $\kappa \mathrm{B} / \mathrm{DNMT} 1$ may be key in Hcy-induced DNA methylation. $N F-\kappa B$ is capable of migrating into the nucleus and activating the transcription of target genes, contemporaneously. It is also involved in the pro-inflammatory response, a first line of defense against infectious diseases, whereas TLR4 is involved in the induction of innate immune and inflammatory responses. A previous study has demonstrated that TLR4-mediated signaling pathways mainly stimulate the activation of NF- $\mathrm{KB}$ (35) and the present study showed that Hcy promoted the mRNA and protein expression of TLR4. According to previous studies and the present study, TLR4/NF- $\mathrm{B} / \mathrm{DNMT} 1$ may be involved in Hcy-induced LOX-1 DNA hypomethylation.

In our previous study, it was demonstrated that folic acid and vitamin $\mathrm{B}_{12}$ are important in regulating the metabolic process of Hcy (20), and Ma et al (36) showed that supplementation of folic acid and vitamin $B_{12}$ in patients with hyperhomocysteinemia (HHcy) reduced the levels of Hcy, suggesting folic acid supplementation may be useful in reducing Hcy levels in high risk patients with HHcy, but may also significantly improve endothelial dysfunction in patients with coronary artery disease. In the present study, it was found that, following supplementation with folate and vitamin $B_{12}$, the damaging effect of Hcy on the ECs was inhibited, and this may be an important method for the remittance of AS caused by Hcy.

In conclusion, the accumulated evidence suggests that Hcy injures ECs via oxidative stress and that TLR4/NF- $\kappa$ B/DNMT1 may be involved in Hcy-induced EC injury by mediating LOX-1 DNA hypomethylation. These findings may be significant in the treatment of EC injury associated with gene expression due to the hypomethylation of gene regulatory regions, with TLR4/NF- $\kappa \mathrm{B} / \mathrm{DNMT} 1$ identified as a novel component in the mechanism. Taken together, the findings reveal a novel role of Hcy in the pathogenesis of AS.

\section{Acknowledgements}

This study was supported by grants from the National Natural Science Foundation of China (grant nos. 81570452, 81460121, $81560120,81560084,81560086,81660047,81660088$ and 81760139).

\section{References}

1. Lynn EG and Austin RC: Hydrogen sulfide in the pathogenesis of atherosclerosis and its therapeutic potential. Expert Rev Clin Pharmacol 4: 97-108, 2011.

2. Puddu P, Puddu GM, Cravero E, Muscari S and Muscari A: The involvement of circulating microparticles in inflammation, coagulation and cardiovascular diseases. Can J Cardiol 26 140-145, 2010.

3. Kolattukudy PE and Niu J: Inflammation, endoplasmic reticulum stress, autophagy, and the monocyte chemoattractant protein-1/CCR2 pathway. Circ Res 110: 174-189, 2012.

4. Suhara T, Fukuo K, Yasuda O, Tsubakimoto M, Takemura Y, Kawamoto H, Yokoi T, Mogi M, Kaimoto T and Ogihara T: Homocysteine enhances endothelial apoptosis via upregulation of Fas-mediated pathways. Hypertension 43: 1208-1213, 2004.

5. Ando K and Fujita T: Role of lectin-like oxidized low-density lipoprotein receptor-1 (LOX-1) in the development of hypertensive organ damage. Clin Exp Nephrol 8: 178-182, 2004.
6. Fujita Y, Yamaguchi S, Kakino A, Iwamoto S, Yoshimoto R and Sawamura T: Lectin-like oxidized LDL receptor 1 is involved in CRP-mediated complement activation. Clin Chem 57: 1398-1405, 2011.

7. Enneman AW, van der Velde N, de Jonge R, Heil SG, Stolk L, Hofman A, Rivadeneira F, Zillikens MC, Uitterlinden AG and van Meurs JB: The association between plasma homocysteine levels, methylation capacity and incident osteoporotic fractures. Bone 50: 1401-1405, 2012.

8. Yoo J, Kim JH, Robertson KD and Medina-Franco JL: Molecular modeling of inhibitors of human DNA methyltransferase with a crystal structure: Discovery of a novel DNMT1 inhibitor. Adv Protein Chem Struct Biol 87: 219-247, 2012.

9. Johnson AA, Akman K, Calimport SR, Wuttke D, Stolzing A and de Magalhães JP: The role of DNA methylation in aging, rejuvenation, and age-related disease. Rejuvenation Res 15: 483-494, 2012.

10. Bhargava S, Parakh R and Srivastava LM: Studies on homocysteine demonstrating its significance as a possible tool for differential diagnosis in occlusive vascular disease. Indian J Clin Biochem 19: 76-78, 2004.

11. Han XB, Zhang HP, Cao CJ, Wang YH, Tian J, Yang XL, Yang AN, Wang J, Jiang YD and Xu H: Aberrant DNA methylation of the PDGF gene in homocysteine-mediated VSMC proliferation and its underlying mechanism. Mol Med Rep 10: 947-954, 2014

12. Laing LV, Viana J, Dempster EL, Trznadel M, Trunkfield LA, Uren Webster TM, van Aerle R, Paull GC, Wilson RJ, Mill J and Santos EM: Bisphenol A causes reproductive toxicity, decreases dnmt1 transcription, and reduces global DNA methylation in breeding zebrafish (Danio rerio). Epigenetics 11: 526-538, 2016.

13. Ye EA and Steinle JJ: miR-146a attenuates inflammatory pathways mediated by TLR4/NF- $\mathrm{KB}$ and $\mathrm{TNF} \alpha$ to protect primary human retinal microvascular endothelial cells grown in high glucose. Mediators Inflamm 2016: 3958453, 2016.

14. Zhang BG, Hu L, Zang MD, Wang HX, Zhao W, Li JF, Su LP, Shao Z, Zhao X and Zhu ZG: Helicobacter pylori CagA induces tumor suppressor gene hypermethylation by upregulating DNMT1 via AKT-NFאB pathway in gastric cancer development. Oncotarget 7: 9788-9800, 2016.

15. Wang Y, Mao L, Zhang L, Zhang L, Yang M, Zhang Z, Li D, Fan C and Sun B: Adoptive regulatory T-cell therapy attenuates subarachnoid hemor-rhage-induced cerebral inflammation by suppressing TLR4/NF-B signaling pathway. Curr Neurovase Res 13: 121-126, 2016.

16. Wang J, Si Y, Wu C, Sun L, Ma Y, Ge A and Li B: Lipopolysaccharide promotes lipid accumulation in human adventitial fibroblasts via TLR4-NF- $\kappa$ B pathway. Lipids Health Dis 11: 139, 2012.

17. Yilmaz N: Relationship between paraoxonase and homocysteine: Crossroads of oxidative diseases. Arch Med Sci 8: 138-153, 2012.

18. Satoh M, Ishikawa Y, Minami Y, Takahashi Y and Nakamura M: Role of Toll like receptor signaling pathway in ischemic coronary artery disease. Front Biosci 13: 6708-6715, 2008.

19. Livak KJ and Schmittgen TD: Analysis of relative gene expression data using real-time quantitative PCR and the 2(-Delta Delta C(T)) method. Methods 25: 402-408, 2001.

20. Jiang Y, Ma S, Zhang H, Yang X, Lu GJ, Zhang H, He Y, Kong F, Yang A, Xu H, et al: FABP4-mediated homocysteine-induced cholesterol accumulation in THP-1 monocyte-derived macrophages and the potential epigenetic mechanism. Mol Med Rep 14: 969-976, 2016.

21. Xu S, Ogura S, Chen J, Little PJ, Moss J and Liu P: LOX-1 in atherosclerosis: Biological functions and pharmacological modifiers. Cell Mol Life Sci 70: 2859-2872, 2013.

22. Takahashi M: Oxidative stress and redox regulation on in vitro development of mammalian embryos. J Reprod Dev 58: 1-9, 2012.

23. Bian D, Liu M, Li Y, Xia Y, Gong Z and Dai Y: Madecassoside, a triterpenoid saponin isolated from Centella asiatica herbs, protects endothelial cells against oxidative stress. J Biochem Mol Toxicol 26: 399-406, 2012.

24. Ou HC, Song TY, Yeh YC, Huang CY, Yang SF, Chiu TH, Tsai KL, Chen KL, Wu YJ, Tsai CS, et al: EGCG protects against oxidized LDL-induced endothelial dysfunction by inhibiting LOX-1-mediated signaling. J Appl Physiol 108: 1745-1756, 2010.

25. Cai JJ, Wen J, Jiang WH, Lin J, Hong Y and Zhu YS: Androgen actions on endothelium functions and cardiovascular diseases. J Geriatr Cardiol 13: 183-196, 2016. 
26. Bonnefont-Rousselot D: Resveratrol and cardiovascular diseases. Nutrients 8: pii: E250, 2016.

27. Thampi P, Stewart BW, Joseph L, Melnyk SB, Hennings LJ and Nagarajan S: Dietary homocysteine promotes atherosclerosis in apoE-deficient mice by inducing scavenger receptors expression. Atherosclerosis 197: 620-629, 2008.

28. Jiang Y, Zhang H, Sun T, Wang J, Sun W, Gong H, Yang B, Shi Y and Wei J: The comprehensive effects of hyperlipidemia and hyperhomocysteinemia on pathogenesis of atherosclerosis and DNA hypomethylation in ApoE ${ }^{-/-}$mice. Acta Biochim Biophys Sin (Shanghai) 44: 866-875, 2012.

29. Ma S, Zhang H, Sun W, Gong H, Wang Y, Ma C, Wang J, Cao C, Yang X, Tian J and Jiang Y: Hyperhomocysteinemia induces cardiac injury by up-regulation of p53-dependent Noxa and Bax expression through the p53 DNA methylation in ApoE (-/-) mice. Acta Biochim Biophys Sin (Shanghai) 45: 391-400, 2013.

30. Rushworth SA, Murray MY, Barrera LN, Heasman SA, Zaitseva L and Macewan DJ: Understanding the role of miRNA in regulating NF-kB in blood cancer. Am J Cancer Res 2: 65-74, 2012.

31. Menon R, Di Dario M, Cordiglieri C, Musio S, La Mantia L, Milanese C, Di Stefano AL, Crabbio M, Franciotta D, Bergamaschi R, et al: Gender-based blood transcriptomes and interactomes in multiple sclerosis: Involvement of SP1 dependent gene transcription. J Autoimmun 38: J144-J155, 2012.
32. Pang X, Liu J, Zhao J, Mao J, Zhang X, Feng L, Han C, Li M, Wang $\mathrm{S}$ and $\mathrm{Wu} \mathrm{D}$ : Homocysteine induces the expression of C-reactive protein via NMDAr-ROS-MAPK-NF- $\kappa \mathrm{B}$ signal pathway in rat vascular smooth muscle cells. Atherosclerosis 236: 73-81, 2014.

33. Zhang Q, Wang HY, Marzec M, Raghunath PN, Nagasawa T and Wasik MA: STAT3- and DNA methyltransferase 1-mediated epigenetic silencing of SHP-1 tyrosine phosphatase tumor suppressor gene in malignant T lymphocytes. Proc Natl Acad Sci USA 102: 6948-6953, 2005.

34. Au-Yeung KK, Woo CW, Sung FL, Yip JC, Siow YL and $\mathrm{O}$ K: Hyperhomocysteinemia activates nuclear factor-kappaB in endothelial cells via oxidative stress. Circ Res 94: 28-36, 2004.

35. Yang J, Su J, Wan F, Yang N, Jiang H, Fang M, Xiao H, Wang $\mathrm{J}$ and Tang $\mathrm{J}$ : Tissue kallikrein protects against ischemic stroke by suppressing TLR4/NF- $\mathrm{KB}$ and activating Nrf2 signaling pathway in rats. Exp Ther Med 14: 1163-1170, 2017.

36. Ma Y, Peng D, Liu C, Huang C and Luo J: Serum high concentrations of homocysteine and low levels of folic acid and vitamin B12 are significantly correlated with the categories of coronary artery diseases. BMC Cardiovasc Disord 17: 37 , 2017. 